\title{
MONOCHROMOSOMAL HYBRIDS FOR THE ANALYSIS OF THE HUMAN GENOME
}

\author{
Raghbir S. Athwal, Ph.D. \\ Department of Microbiology and Molecular Genetics \\ UMDNJ-New Jersey Medical School
}

$\mathrm{DOE} / \mathrm{ER} / 60866--2$

DE9 I 005006

\section{PROJECT SUMMARY}

In this research project we have proposed to develope rodent/human hybrid cell lines each containing a single different human chromosome. The human chromosomes will be marked with Ecogpt and stably maintained by selection in the hybrid cells.

The experimental approach to produce the proposed cell lines involve the following: We will first transfer a cloned selectable marker, Ecogpt (an E. coli gene for xanthine-guanine phosphoribosyltransferase: XGPRT) to normal diploid human cells using a retroviral vector. The transferred gene will integrate at random into multiple sites in the recipient cell genome. Clonal cell lines from independent transgenotes will each carry the selectable marker integrated into a different site and perhaps a different chromosome. The chromosome carrying the selectable marker will then be transferred further to mouse cells by microcell fusion. In addition we will also use directed integration of Ecogpt into the chromosome present in rodent cells, otherwise not marked with a selectable marker. This will allow us to complete the bank of proposed cell line.

The human chromosome, since will be marked with a selectable marker can be transferred to any other cell line of interest for complementation analysis. Clones of each cell line, containing varying size segments of the same chromosome produced by selection for the retention or loss of the selectable marker following X-irradiation or by metaphase chromosome transfer method will facilitate physical mapping and determination of gene order on a chromosome.

\section{DISCLAIMER}

\footnotetext{
This report was prepared as an account of work sponsored by an agency of the United States Government. Neither the United States Government nor any agency thereof, nor any of their employees, makes any warranty, express or implied, or assumes any legal liability or responsibility for the accuracy, completeness, or usefulness of any information, apparatus, product, or process disclosed, or represents that its use would not infringe privately owned rights. Refermanufactur:r, or otherwice by trade name, trademark, mendation, or favoring by the United necessarily constitute or imply its endorsement, recomand opinirns of authors expressed herein Government or any agency thereof. The views United States Government or any agency theref not necessarily state or reflect those of the
} 
Objective: The objective of the research project is to transfer individual human chromosomes to mouse and/or Chinese hamster cells to produce hybrid cell lines each harboring a single different human chromosome. The human chromosome present in rodent cells will be marked with a dominant selectable marker and maintained by selection. These cell lines will serve as a national resource for mapping and sequencing the human genome.

Methodology: The details of methodology has previously been described in the original grant application. In summary, we will first transfer a dominant selectable marker into a human lymphoblastoid (L1265, L1343 and L8282) and a normal fibroblast cell tine using retroviral vectors. The retroviral vectors available in our laboratory are modified to clone genes for xanthine guanine phosphoribosyl transferase (Ecogpt) and resistance to antibiotic hygromycine (hygro) together. These vectors are transfected into a packaging cell line (PA $317)$ to produce infective virions. The vectors packaged as virus particles are infected into human cells to produce a bank of cell lines each containing a single different marked chromosome. The marked human chromosomes are then transferred to rodent cells by the method of microcell fusion. An outline of the methodology is given in figure 1.

\section{Progress Report: The progress made towards the final goal since the inception of the project is} as follows:

1. We have constructed the necessary vector system for integrating the selectable marker into the human chromosomes.

2. We have recovered at least 102. independent clones of a fibroblast cell line each carrying the marker integrated into a different site. These clones are being analyzed to identify 24 cell lines each carrying the marker integrated into different chromosome.

3. A mixed population of lymphoblastoid cells carrying the selectable marker has also been produced. These cells will be fused with a mouse cell line to rescue the marked chromosome into mouse/human hybrid cells.

4. We have developed an experimental strategy using PCR technology to rescue the human DNA sequences that flank the integrated selectable marker. DNA sequences recovered from independent clones, each carrying the marker at a different site, are us $=d$ as probes to identify the chromosome of origin. This will allow us to identify 24 clonal cell lines each carrying the selectable marker into a different chromosome. Once identified, each chromosome will be transferred by microcell fusion into mouse or hamster cells. We have already applied this system to identify marked chromosomes in six clones.

5. Using marked lymphoblastoid cells and clones of fibroblasts we have produced a total of 12 monochromosomal hybrids to date. These hybrids include:

\begin{tabular}{llr} 
Hybrid & Description & Human Chror \\
\cline { 3 - 4 } RA2-1 & Mouse/Human & 2 \\
RA 7 & Mouse/Human & 7 \\
RA 9 & Mouse/Human & 9 \\
RA 15 & Mouse/Human & 15 \\
RA-H 16 & Chinese Hamster/Human & 16 \\
RA 17 & Mouse/Human & 17
\end{tabular}

In addition, there are six other hybrids in which identity of the human chromosome is not confirmed. 
6. In parallel to these studies we have developed a method of DNA fingerprinting using PCR based DNA amplification for the identification of different human chromosomes. DNA fingerprinting allows the identification and mapping of subchromosomal fragments present in different hybrids.

\section{Papers in Preparation}

1. Sidhu, M.S., B. Helen and R.S. Athwal. Selective DNA Amplification: A method for chromosome fingerprinting and identification. (Prepared for publication in Proceedings of National Academy of Sciences, U.S.)

2. Sidhu, M.S., A.K. Sandhu, F. Chen and R.S. Athwal. PCR amplification and cloning of DNA segment flanking an integrated marker: Identification of chromosome carrying the selectable marker in human cells. (Prepared for publication in Proceedings of National Academy of Sciences, U.S.)

3. Helen, B., P. Kaur and R.S. Athwal. Microcell mediated transfer of individual human chromosomes to rodent cells: Production of monochromosomal hybrids. 


\section{Fig 1}

\section{EXPERIMENTAL APPROACH TO PRODUCE MOUSE/HUMAN}

MONOCHROMOSOMAL RYBRTOS
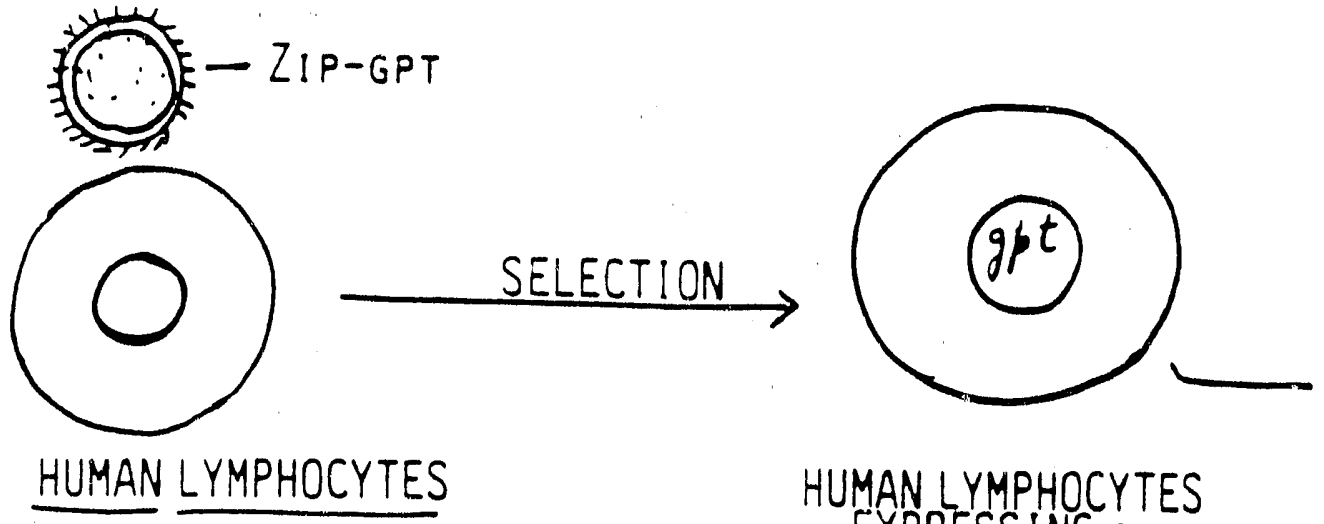

HUMAN LYMPHOCYTES

EXPRESSING GPT

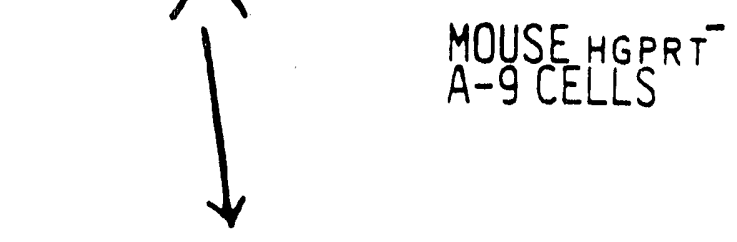

SELECTION IN MX

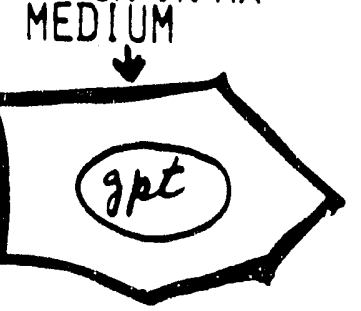

MOUSE/HUMAN HYBRIDS EXPRESSING GPT

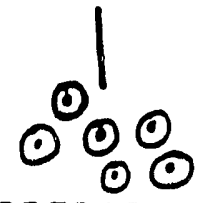

MICROCELL PREPARATION

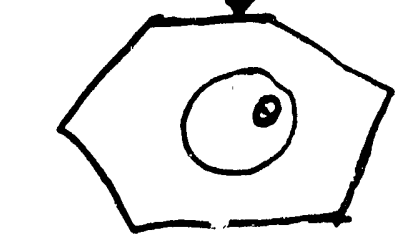

MOUSE A9 CELLS

$\downarrow$

SELECTION IN MX MEDIUM

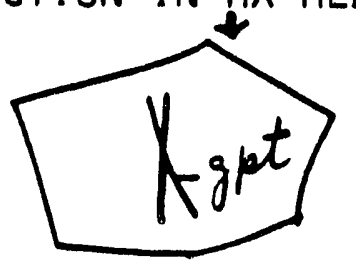

MONOCHROMOSOMAL HYBRIDS 
DOE F538 (5-86)

U. S. DEPARTMENT OF ENERGY

OMB Control No.

\section{NOTICE OF ENERGY RD\&D PROJECT}

1. Descriptive TITLE of work

(i 50 characters including spaces)

Monochromosomal Hybrids for the Analysis of Human Genome

2. CONTRACT or

grant number

2A. MASTER contract number (GOCO's)

DE-FG02-89ER60866

2B. Responsible PATENT office

4. Original contract start date

$4 \mathrm{~A}$. Current contract start date

$\frac{\text { Imly } 1,1989}{\text { February } 1,1991}$

5. Work STATUS
$\square$ Proposed
X Renewal
$\square$ New
$\square$ Terminated

5A. Manpower (FTE)

6. Name of PERFORMING organization University of Medicine and Dentistry of New Jersey-New Jersey Medical School

6A. DEPARTMENT or DIVISION Microbiology and Molecular Genetics

6B. Street Address

185 South Orange Ave.
6C. City, State, Zip Code

Newark, New Jersey 07103-2714

7. Circle only one code for TYPE of Organization Pe:forming R\&D:

$\mathrm{CU}$ - College, university, or trade school

FF - Federally funded RD\&D centers or laboratory operated for an agency of the $U$. S.

Government

IN - Private industry

NP - Foundation r: laboratary not operated for profit

ST - Regional, state or local government facility

TA - Trade or professional organization

US - Federal agency

$X X$ - Other

EG - Electric or gas utility

8A. Contractor's PRINCIPAL INVESTIGATOR/s or project manager Name/s (Last, First, MI)_Athwal,_Raghbir_S.

8B. PHONE/s (in urder of PI names with commercial followed by FTS)

Comm. 201-456-5215;FTS : Comm. ; FTS

$8 \mathrm{C}$. PI/s address (if different from that of Performing Organization) 
9. DOE SUPPORTING Organization (DOE Assistant Secretary and office sponsoring the work;

technical monitor; and administrative monitor).

9A. PROGRAM division or office

(full name) Office of Health and Environmental Research

ER-72

9B. TECHNICAL monitor (Last, First, MI) Barnhart, Benjamin J.

9C. Address Office of Health \& Environ. Res.- 9D. Phone

Program Office Code

Office of Energy Research, لl_ S Dept of Energy

Washington, DC 20585

9E. ADMINISTRATIVE monitor (Last, First, MI)

10. FUNDING in thousands of dollars (KS). Funds represent budget obligations for operating and capital equipment (FY runs October 1 - September 30 ).

\begin{tabular}{|l|l|l|}
\hline \multicolumn{1}{|c|}{ Funding organization(s) } & Current FY & Next FY \\
\hline A. DOE & & \\
\hline B. & & \\
\hline C. & & \\
\hline
\end{tabular}

10D. Does the current FUNDING cover more than one year's work?

Yes

No $\mathrm{X}$

E. If yes, provide dates (from when to when)

11. Descriptive SUMMARY of work. Enter a Project Summary using complete sentences limited to 200 words covering the following: Objective(s), state project objectives quantifying where possible (e.g., "The project objective is to demonstrate $95 \%$ recoveiy of sulphur from raw gas with molten salt recycling at a rate of one gallon per minute."l; approach, describe the technical approach used (how the work is to be done); expected product/results, describe the final products or results expected from the project and their importance and relevance.

\section{PROJECT SUMMARY}

In this research project we have proposed to develop rodent/human hybrid cell lines each containing a single different human chromosone. The human chromosomes will be marked with Ecogpt and stably maintained by selection in the hybrid cells.

The experimental approach to produce the proposed cell lines involve the following: We will first transfer a cloned selectable marker, Ecogpt (an E. coli gene for xanthine-guanine phosphoribosyltransferase: XGPRT) to normal dip 1oid human cells using a retroviral vector. The transferred gene will integrate at random into multiple sites in the recipient cell genome. Clonal cell 1 ines from independent transgenotes will each carry the selectable marker integrated into a different site and perhaps a different chromosome. The chromosome carrying the selectable marker will then be transferred further to mouse cells by microcell fusion. In addition, we will also use directed integration of Ecogpt into the chromosome present in rodent cells, otherwise not marked with a selectable marker. This will allow us to complete the bank of proposed cell 1 ine.

The human chromosome, since will be marked with a selectable marker can be transferred to any other cell line of interest for complementation analysis. clones of each cell line, containing varying size segments of the same chromosome produced by selection for the retention or loss of the selectable marker following $X$-irradiation or by metaphase chromosome transfer method will facilitate physical mapping and determination of gene order on a chromosome. 
12. PURLICATIONS available to the public. List the five most descriptive publications that have resulted from this project in the last year that are available to the public. (Include author, title, where published, year of publication, and any uther information you have to complete full bibliographic citation.) Use the back of this form or additional sheets if necessary.

1, Sidhu, M.S., B. Helen and R.S. Athwal. Selective DNA Amplification: A method for chromosome fingerprinting and identification. (Prepared for publication in Proceedings of National Academy of Sciences, U.S.)

2. Sidhu, M.S., A.K. Sandhu, F. Chen and R.S. Athwal. PCR amplification and cloning of DNA segment flanking an integrated marker: Identification of chromosome carrying the selectable marker in human cells. (Prepared for publication in Proceedings of National Academy of Sciences, U.S.)

3. Helen, B., P. Kaur and R.S. Athwal. Microcell mediated transfer of individual human chromosomes to rodent cells: Production of monochromosomal hybrids.

13. KEYWORDS (Listed five terms describing the technical aspects of the project. List specific chemicals and CAS number, if applicable.)

Mouse/Human Monochromosomal Hybrids

Microcel1 Fusion

Chromosome Transfer

14. RESPONDENT. Name and address of purson filling out the Form 538. Give telephone number, including extension (if you have FTS number, please include it) at which person can be reached. Record the date this form was completed or updated. The information in Item 14 will not be published.

Respondent's Name:_Raghbir S. Athwal, Ph.D__ Phone No.: 201-456-5215 Date:

Street: 185 South Orange Avenue

City: Neviark

State: New Iersey

Zip: $07103-2714$ 
15. Additional space for furnishing information in items 1 to 14. (Indicate item numbers to which answers apply.)

Item No.

NOTICE: Return this form to the office indicated in the reporting requirements for your award agreement covering this project. If you have completed a similar programmatic office project description during the current Fiscal Year, complete only the new data elements on this form and send it and a copy of the description completed earlier to Department of Energy, Office of Scientific Information, P ?. Box 62, Oak Ridge, TN 37831. 

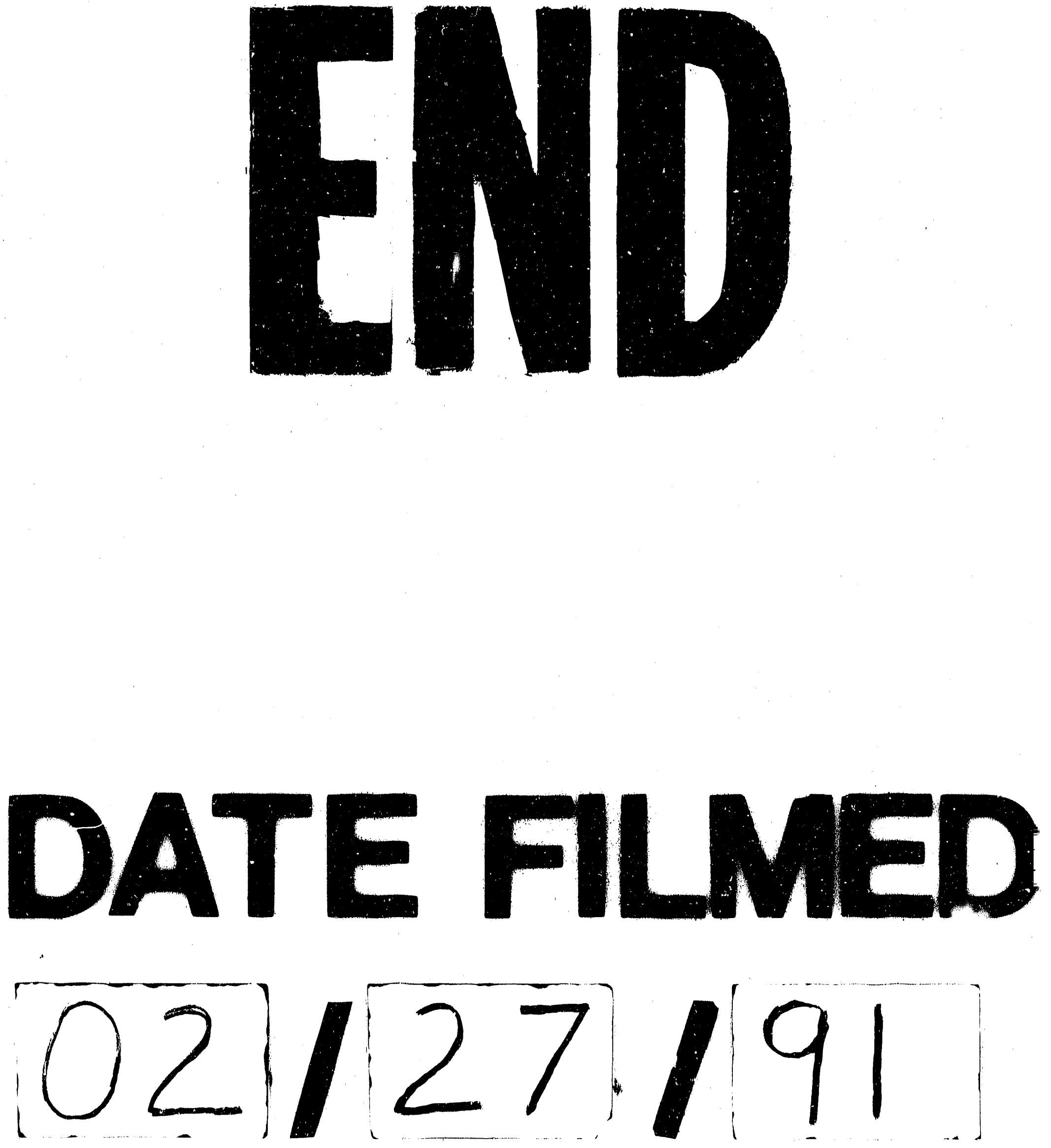


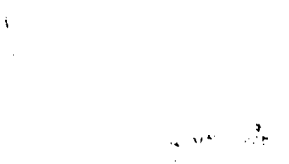

